\title{
$\mathrm{NaA}$ zeolite membranes on modified porous stainless steel supports: a comparative study of different $\mathrm{SiO}_{2}$ sources
}

\author{
Yohana Martinez Galeano $^{1}$ (D) . Ana M. Tarditi $^{1}$ (D) . Laura M. Cornaglia ${ }^{1}$ (D
}

Received: 16 April 2019 / Revised: 10 August 2019 / Accepted: 14 October 2019

C) Associação Brasileira de Engenharia Química 2020

\begin{abstract}
The deposition of a NaA zeolite layer on porous stainless steel substrates was optimized in order to obtain composite membranes for hydrogen separation. The effect of the silica source on NaA zeolite crystallinity and morphology was studied using two synthesis routes: concentrated gel and clear solution. The optimized synthesis conditions were applied for the synthesis of $\mathrm{NaA}$ zeolite layers on top of porous stainless steel disks or on the outer surface of tubular supports. SEM and XRD measurements confirmed that the use of rice husk allowed obtaining defect free and pure phase NaA zeolite membranes. Selectivity values similar to those published for NaA zeolite membranes based on ceramic substrates were obtained using zeolite layers deposited on porous stainless steel tubes. From the curve fitting of the experimental data, the contribution of zeolitic and non-zeolitic flux was estimated. For the membranes synthesized from a concentrated gel, $\mathrm{H}_{2}$ showed a predominated contribution of the zeolitic flux.
\end{abstract}

Keywords Rice husk $\cdot$ NaA zeolite $\cdot$ Porous stainless steel

\section{List of symbols}

A Model parameter $\left(\mathrm{mol} \mathrm{m}^{2} \mathrm{~s}\right)$

$A_{t} \quad$ Total area of the membrane $\left(\mathrm{m}^{2}\right)$

$A_{z} \quad$ Zeolite open pore area $\left(\mathrm{m}^{2}\right)$

$B \quad$ Model parameter $\left[\left(\mathrm{mol} \mathrm{K} \mathrm{J}^{-1}\right)^{0.5}\right]$

$b_{i} \quad$ Langmuir adsorption constant of component $\mathrm{i}$ $\left(\mathrm{Pa}^{-1}\right)$

$b_{i, 0} \quad$ Langmuir adsorption constant of component $\mathrm{i}$ at reference temperature $\left(\mathrm{Pa}^{-1}\right)$

$C \quad$ Model parameter $\left(\mathrm{mol} \mathrm{K} \mathrm{m} \mathrm{J}{ }^{-1}\right)$

$D_{i, 0} \quad$ Diffusivity of component $\mathrm{i}$ at zero loading $\left(\mathrm{m}^{2} \mathrm{~s}^{-1}\right)$

$E_{i}^{D} \quad$ Activation energy of component i $\left(\mathrm{J} \mathrm{mol}^{-1}\right)$

$M \quad$ Molecular weight $\left(\mathrm{g} \mathrm{mol}^{-1}\right)$

$N_{i, k} \quad$ Knudsen flux $\left(\mathrm{mol} \mathrm{m}^{-2} \mathrm{~s}^{-1}\right)$

$N_{i, t} \quad$ Total flux through the membrane $\left(\mathrm{mol} \mathrm{m}^{-2} \mathrm{~s}^{-1}\right)$

$N_{i, v} \quad$ Viscous flux $\left(\mathrm{mol} \mathrm{m}^{-2} \mathrm{~s}^{-1}\right)$

Electronic supplementary material The online version of this article (https://doi.org/10.1007/s43153-020-00024-y) contains supplementary material, which is available to authorized users.

Laura M. Cornaglia

lmcornag@ fiq.unl.edu.ar

1 Instituto de Investigaciones en Catálisis y Petroquímica, INCAPE, Facultad de Ingeniería Química, Universidad Nacional del Litoral, CONICET, Santiago del Estero 2829, 3000 Santa Fe, Argentina
$N_{i, z} \quad$ Molar flux of component $\mathrm{i}$ through zeolite pores $\left(\mathrm{mol} \mathrm{m} \mathrm{m}^{-2} \mathrm{~s}^{-1}\right)$

$P \quad$ Pressure $(\mathrm{Pa})$

$P_{i} \quad$ Partial pressure of component i $(\mathrm{Pa})$

$P_{m} \quad$ Mean pressure $(\mathrm{Pa})$

$q_{s} \quad$ Saturation adsorption capacity $\left(\mathrm{mol} \mathrm{kg}^{-1}\right)$

$R \quad$ Ideal gas constant $\left(\mathrm{J} \mathrm{mol}^{-1} \mathrm{~K}^{-1}\right)$

$r_{i} \quad$ Defect size $(\mathrm{m})$

$T$ Temperature (K)

$T_{0} \quad$ Reference temperature (K)

Greek letters

$\alpha_{i / j} \quad$ Ideal separation factor

$\Delta H_{i} \quad$ Enthalpy of adsorption of component $\left(\mathrm{J} \mathrm{mol}^{-1}\right)$

$\Delta X \quad$ Thickness of zeolite film (m)

$\checkmark \quad$ Viscosity (Pa s)

$\Pi_{i} \quad$ Permeance of component $\mathrm{i}\left(\mathrm{mol} \mathrm{m}^{-2} \mathrm{~s}^{-1} \mathrm{~Pa}^{-1}\right)$

$\Pi_{j} \quad$ Permeance of component $\mathrm{j}\left(\mathrm{mol} \mathrm{m}^{-2} \mathrm{~s}^{-1} \mathrm{a}^{-1}\right)$

$\rho \quad$ Zeolite density $\left(\mathrm{kg} \mathrm{m}^{-3}\right)$

$\tau \quad$ Membrane tortuosity

\section{Introduction}

Over the last few decades, the deposition of zeolite layers has become a focus of attention due to the possibility of their being used as membranes, sensors, electrodes and structured 
catalysts, among other applications. These aluminosilicates are ideal materials for membrane synthesis considering their well-organized and uniform pore structure. Among all types of zeolites, the NaA phase has attracted a great deal of attention due to its application for gas and liquid separations (Nair and Tsapatsis 2003). This zeolite has a cubic structure with a pore size of $0.41 \mathrm{~nm}$, and is suitable to separate small molecules such as hydrogen by the molecular sieve mechanism (Huang et al. 2012; Xu et al. 2018).

Even though different methods have been reported for zeolite film deposition (Xu et al. 2018), two routes are mainly used: in situ hydrothermal synthesis and secondary growth (Xu et al. 2018). The latter, a two-step method, is more reproducible since it allows decoupling the nucleation and growth stages, improving the crystallization kinetics (Berenguer-Murcia et al. 2005). Although many attempts have been made to improve zeolite deposition, there are several factors affecting the morphological, structural and physicochemical properties of the zeolite layer such as composition of the reactant mixture, temperature, raw materials and physical and chemical properties of the porous support (Feng et al. 2015) that still need to be optimized. The source of silicon is one of these variables and it has not been widely analyzed for the synthesis of NaA zeolite membranes. Zhang et al. (2013a, b) obtained powders with different particle size distributions, between 120 and 490, 110 and 500, 80 and 320 and 110 and $405 \mathrm{~nm}$, using water glass, tetraethylorthosilicate (TEOS), fumed silica and colloidal silica, respectively, as silicon sources. On the other hand, Mohamed et al. (2009) reported the formation of a pure $\mathrm{NaA}$ zeolite phase at $383 \mathrm{~K}$ using fumed silica, colloidal silica or sodium metasilicate, while the use of TEOS yielded an amorphous product. Natural sources such as kaolin were also studied for the zeolite $\mathrm{NaA}$ synthesis. Ayele et al. (2016) reported the successful synthesis of zeolite $\mathrm{NaA}$ with raw and purified kaolin; the authors found that despite the fact that purified kaolin yields better quality zeolite $\mathrm{A}$, raw kaolin was also promising.

Silica extracted from rice husk ash is a viable alternative to the commercial silicon sources. The use of these biomass residues generates an additional environmental benefit and could be used for the production of valuable silica-based materials like zeolites and silicates. The silica extracted from rice husk has been used for the synthesis of several zeolites such as $\mathrm{NaX}$ (FAU) (Katsuki and Komarneni 2009), NaA (LTA) (Katsuki and Komarneni 2009) and LTJ (Ng et al. 2015); however, few articles have reported the synthesis of composite membranes using this silica source (Bhavornthanayod and Rungrojchaipon 2009).

The permselective properties of zeolite membranes are strongly affected by the intercrystalline defects present in the selective film. These defects also known as non-zeolite pores can be formed during the growth of the film or during the thermal treatments prior to the permeation measurements.
Due to the coexistence of zeolite and non-zeolite pores, three main diffusion mechanisms could be simultaneously present in these membranes: (1) Zeolitic flux (through zeolite pores), (2) Knudsen flux (through the non-zeolite pores), (3) Viscous flux (through non-zeolite pores) (Hosseinzadeh Hejazi et al. 2011). One of the major factors affecting composite membrane performance is the physicochemical properties of the support. Among different materials used as substrates (ceramic, metallic, glass), porous stainless steel shows high potential considering its mechanical and thermal resistance, better flexibility to assemble in the permeation module and low cost. Regarding the latter, it is known that about $70 \%$ of the membrane cost is due to the substrate (Pina et al. 2011); hence, the development of membranes using less expensive supports with high chemical and mechanical stability is a challenge for the economic feasibility of composite membranes. In this sense, the use of stainless steel as support for the synthesis of zeolite $\mathrm{T}$ and chabazite membranes has been studied (Hu et al. 2016; Zhang et al. 2014). Some authors reported the reusability of porous stainless steel supports, showing high reproducibility of the membrane performance after reusing of the supports (Zhang et al. 2014). In a recent publication, $\mathrm{NaA}$ zeolite membranes were synthesized on top of reusable porous stainless steel supports (Gui et al. 2019); the membranes presented a separation performance comparable to that of membranes prepared on conventional ceramic supports, with the advantage of presenting higher mechanical strength and easier assembly (Gui et al. 2019).

The goal of the present work was to develop NaA zeolite membranes supported on porous stainless steel using several $\mathrm{SiO}_{2}$ sources: fumed silica, colloidal silica and $\mathrm{SiO}_{2}$ extracted from rice husks. The development of zeolite membranes on porous stainless steel was investigated due to the fact that these supports have high chemical, mechanical stability, facile assembly and can be easily scaled up. Besides, we studied the effect of the support functionalization with APTES on the membrane morphology for each silicon source employed in the membrane synthesis. A comparison between the synthesis from a concentrated gel and a clear solution was performed. The properties of the zeolites were characterized by X-ray diffraction, X-ray fluorescence spectrometry and scanning electron microscopy. The single gas permeation properties of the membranes deposited on the outer surface of stainless steel supports were analyzed as a function of temperature. The contribution of the zeolitic and non-zeolitic flux through the membranes was obtained from the fit of the experimental data. 


\section{Experimental section}

\section{NaA zeolite synthesis from a concentrated gel}

$\mathrm{NaA}$ zeolite was hydrothermally synthesized in a polypropylene vessel immersed in a thermal bath. The molar composition of the synthesis gel was $1 \mathrm{Al}_{2} \mathrm{O}_{3}: 3.5 \mathrm{SiO}_{2}: 8.4$ $\mathrm{Na}_{2} \mathrm{O}: 268 \mathrm{H}_{2} \mathrm{O}$. For the synthesis, a solution of sodium aluminate was prepared dissolving $3.85 \mathrm{~g}$ of $\mathrm{NaOH}$ and $3.03 \mathrm{~g}$ of $\mathrm{Na}_{2} \mathrm{Al}_{2} \mathrm{O}_{4}$ in $60 \mathrm{~mL}$ of deionized water. The silica suspension was obtained by dissolving $1.78 \mathrm{~g}$ of the $\mathrm{SiO}_{2}$ source (Aerosil $200^{\circledR}$ or $\mathrm{SiO}_{2}$ extracted from rice husk) in $26.7 \mathrm{~mL}$ of deionizer water. The synthesis was carried out at $363 \mathrm{~K}$ during $8 \mathrm{~h}$ following the procedure described in our previous publication (Martínez Galeano et al. 2016).

For the extraction of silica, the rice husks were soaked in $3 \mathrm{M} \mathrm{HCl}$ solution at $373 \mathrm{~K}$ during $1 \mathrm{~h}$ under stirring, maintaining a ratio of $200 \mathrm{~mL}$ of solution per $10 \mathrm{~g}$ of solid. After leaching, they were washed with deionized water several times and dried at $393 \mathrm{~K}$ overnight, followed by calcination at $823 \mathrm{~K}$ during $6 \mathrm{~h}$.

\section{$\mathrm{NaA}$ zeolite synthesis from a clear solution}

The synthesis was performed by the preparation of two solutions: for the aluminate solution, $21.77 \mathrm{~g}$ of $\mathrm{NaOH}$ and $0.91 \mathrm{~g}$ of $\mathrm{Na}_{2} \mathrm{Al}_{2} \mathrm{O}_{4}$ were dissolved in $50 \mathrm{~mL}$ of deionized water and, for the silica suspension, $1.67 \mathrm{~g}$ of the $\mathrm{SiO}_{2}$ source was mixed with $50 \mathrm{~mL}$ of deionized water. Fumed silica (Aerosil $200^{\circledR}$ ) and a colloidal suspension (LUDOX AS40 ${ }^{\circledR}$ ) were used as silica sources. The solutions were homogenized separately and then the aluminate solution was added to the silica mixture, obtaining a clear solution with the molar composition equal to $1 \mathrm{Al}_{2} \mathrm{O}_{3}: 5 \mathrm{SiO}_{2}: 50 \mathrm{Na}_{2} \mathrm{O}: 1000 \mathrm{H}_{2} \mathrm{O}$ (Huang et al. 2010). In order to optimize the formation of a NaA pure phase, the effects of aging time ( 0 or $20 \mathrm{~h})$, temperature (333 and $363 \mathrm{~K}$ ) and synthesis time ( 8 and $24 \mathrm{~h}$ ) were analyzed. Once the synthesis time was complete, the powder was filtered and washed successively with deionized water until neutral $\mathrm{pH}$. The product was dried overnight at $393 \mathrm{~K}$.

Table 1 summarizes the synthesis conditions of the powders synthesized from a concentrated gel and a clear solution. The nomenclature of the studied samples follows the code: NaA_W_X_Y_Z where W refers to the Si source (Aerosil, $\mathrm{SiO}_{2}$-Rice or LUDOX), $\mathrm{X}$ to the aging time, $\mathrm{Y}$ to the synthesis temperature and $\mathrm{Z}$ to the synthesis time, $\mathrm{CG}$ : concentrated gel and CS: clear solution.

\section{Membrane preparation}

For the synthesis of NaA zeolite membranes, two synthesis routes (concentrated gel or clear solution) were evaluated using porous stainless steel tubes and disks as supports, both provided by Mott Corporation. The zeolite was synthesized by secondary growth on top of the disks and on the outer surface of the tubes, following the seeding procedure described in our previous publication (Martínez Galeano et al. 2016). Before the zeolite deposition, the supports were functionalized with 3-aminopropyltriethoxysilane (APTES) in order to improve the adhesion of zeolite crystals to the support surface (Martínez Galeano et al. 2016). To avoid deposition of zeolite materials on the opposite side of the disk, they were covered with Teflon tape. The tubes were placed vertically in the synthesis gel and the disk horizontally and the hydrothermal synthesis was carried out at $363 \mathrm{~K}$ during $8 \mathrm{~h}$, under stirring. Afterwards, they were washed with deionized water and dried overnight at $393 \mathrm{~K}$. Vacuum was applied in the last hydrothermal deposition stage in order to improve the homogeneity of the zeolite layer. For the synthesis using a clear solution, the effect of the APTES concentration and the use of a stainless steel autoclave at $333 \mathrm{~K}$ were analyzed, starting from the conditions optimized for the powder preparation.

\section{Sample characterization}

The chemical composition of the $\mathrm{SiO}_{2}$ extracted from the rice husk was determined by X-ray fluorescence spectrometry (XRF). An EDX-720 Shimadzu energy dispersive X-ray spectrometer was used for the analysis. This technique was
Table 1 Main characteristics of the powder synthesis from a concentrated gel and a clear solution

\begin{tabular}{|c|c|c|c|c|c|}
\hline Sample ${ }^{\mathrm{a}}$ & Synthesis route & Si source & $\begin{array}{l}\text { Tem- } \\
\text { perature } \\
(\mathrm{K})\end{array}$ & Aging time (h) & $\begin{array}{l}\text { Synthesis } \\
\text { time (h) }\end{array}$ \\
\hline NaA_Aerosil_0_363_8CG & Concentrated gel & Aerosil $200^{\circledR}$ & 363 & - & 8 \\
\hline NaA_SiO 2 -Rice_0_363_8CG & Concentrated gel & $\mathrm{SiO}_{2}$-Rice & 363 & - & 8 \\
\hline NaA_Aerosil_20_333_24CS & Clear solution & Aerosil $200^{\circledR}$ & 333 & 20 & 24 \\
\hline NaA_LUDOX_20_333_24CS & Clear solution & LUDOX AS40 ${ }^{\circledR}$ & 333 & 20 & 24 \\
\hline
\end{tabular}

$C G$ concentrated gel, $C S$ clear solution

${ }^{a}$ Nomenclature: NaA_W_X_Y_Z where W refers to the Si source (Aerosil, $\mathrm{SiO}_{2}$-Rice or LUDOX), X to the aging time, $\mathrm{Y}$ to the synthesis temperature and $\mathrm{Z}$ to the synthesis time 
also used for the analysis of the chemical composition of the $\mathrm{NaA}$ zeolite synthesized.

The X-ray diffraction patterns of the synthesized powders and membranes were obtained with an XD-D1 Shimadzu diffractometer with a $\mathrm{Cu} K \alpha$ radiation $(\lambda=1.542 \AA)$ at $30 \mathrm{kV}$ and $40 \mathrm{~mA}$.

The morphology of the zeolite powders and the surface of the membranes were determined using a scanning electron microscope, JEOL model JSM-35C.

\section{Gas permeation properties}

$\mathrm{H}_{2}, \mathrm{CO}_{2}$ and $\mathrm{CH}_{4}$ single gas permeation experiments were performed in tubular membranes using the permeator described elsewhere (Martínez Galeano et al. 2016). Before the measurements, the membranes were heated at $503 \mathrm{~K}$ in hydrogen flux during 2 days so as to eliminate the water occluded in the zeolite structure. The perm-selective properties of the membranes were studied as a function of temperature at $100 \mathrm{kPa}$ of pressure difference between the permeate and retentate, which was controlled with a back-pressure regulator. For the single gas measurements the permeated flux was measured at atmospheric conditions using a bubble flux meter. The ideal separation factor $\left(\alpha_{i / j}\right)$ of $\mathrm{H}_{2}$ from $\mathrm{CO}_{2}$ or $\mathrm{CH}_{4}$ was defined as the ratio of the single gas permeances, as shown in Eq. 1:

$\alpha_{i / j}=\frac{\Pi_{i}}{\Pi_{j}}$

where $\Pi_{i}$ is the permeance of component i $\left(\mathrm{mol} \mathrm{m}^{-2} \mathrm{~s}^{-1}\right.$ $\left.\mathrm{Pa}^{-1}\right)$ and $\Pi_{j}$ is the permeance of component $\mathrm{j}\left(\mathrm{mol} \mathrm{m}^{-2}\right.$ $\left.\mathrm{s}^{-1} \mathrm{~Pa}^{-1}\right)$.

\section{Results and discussion}

With the goal of obtaining $\mathrm{NaA}$ zeolite membranes on top of porous stainless steel supports, we studied the effect of the silicon source on the NaA zeolite synthesis. In the first section, we present the results and discussion of the optimization of NaA zeolite powders using several silicon sources. Then, we analyze the influence of the synthesis conditions on the zeolite layer deposition and their morphological and structural properties and finally, the permeation properties of the best membranes are presented and discussed.

\section{Optimization of $\mathrm{NaA}$ zeolite powders}

The powders synthesized were analyzed by means of X-ray diffraction for the identification of the crystalline phases present in the samples. The XRD patterns of the powders synthesized from a concentrated gel are shown in Fig. 1

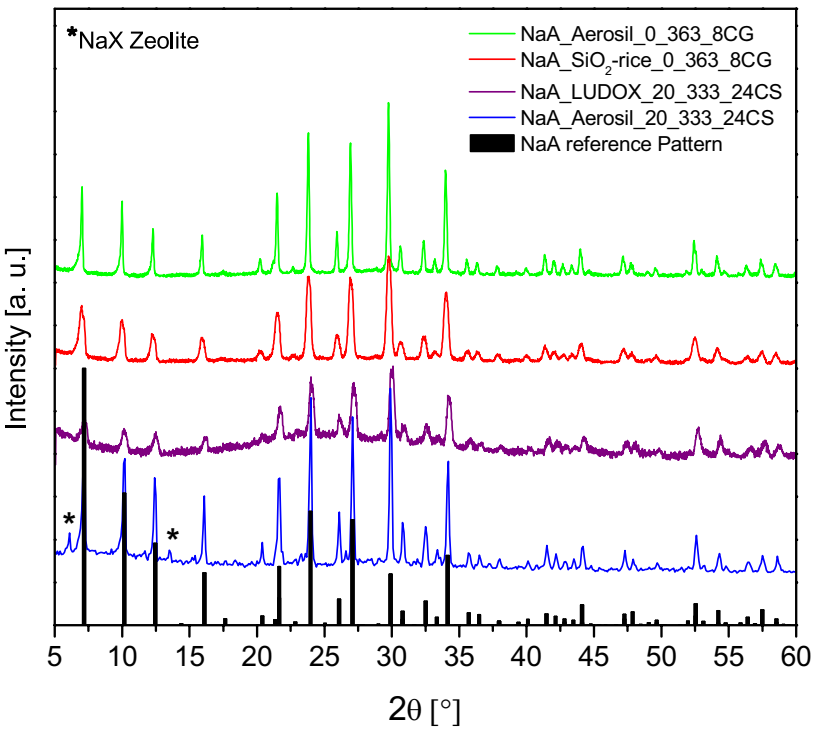

Fig. 1 XRD diffraction patterns of the powders synthesized using Aerosil $200^{\circledR}, \mathrm{LUDOX}$ and $\mathrm{SiO}_{2}$-Rice

and the effect of the Si sources on the morphology of the $\mathrm{NaA}$ crystals is summarized in Fig. 2. Note that all samples showed the characteristic reflection peaks assigned to the NaA zeolite. However, the NaA_Aerosil_20_333_24CS sample showed additional peaks located at $2 \theta=6.1^{\circ}$ and $13.5^{\circ}$; these reflections corresponded to the $\mathrm{NaX}$ zeolite (Database of Zeolite Structures).

The crystals obtained using the $\mathrm{SiO}_{2}$ extracted from rice husk (NaA_SiO 2 -Rice_0_363_8CG sample) showed a cubic morphology, characteristic of the NaA zeolite, with sharp edge and a wide particle size between 1 and $4 \mu \mathrm{m}$ (Fig. 2a). It should be noted here that the $\mathrm{SiO}_{2}$ obtained from rice husks presented a Si composition as high as $96.83 \%$ with $\mathrm{Al}(2.91 \%)$ and $\mathrm{Fe}(0.17 \%)$ as the main contaminants and the XRD analysis showed the typical pattern of amorphous silica (not shown). On the other hand, when Aerosil $200^{\circledR}$ was used as the silica source (NaA_Aerosil_0_363_8CG sample), truncated edge cubic crystals were obtained with a narrow particle size (Fig. 2b).

This difference could be related to the physical properties of the $\mathrm{SiO}_{2}$ sources like particle size and dissolution rate in the alkali medium. These properties are directly related to the polymerization rate, the distribution and saturation degree of the silicate species present in the synthesis gel giving different concentrations of nuclei in the gel matrix. Meise and Schwochow (1973) reported a marked difference in particle size using diverse silica sources, which was related to the different reactivities attributed to the dissimilar specific surface areas. In our case, the $\mathrm{SiO}_{2}$ extracted from rice had a surface area of about $300 \mathrm{~m}^{2} \mathrm{~g}^{-1}$, while for Aerosil $200^{\circledR}$ it was $200 \mathrm{~m}^{2} \mathrm{~g}^{-1}$. As mentioned 
Fig. 2 Effect of silica source on the morphology of the $\mathrm{NaA}$ zeolite crystals obtained from a concentrated gel: a $\mathrm{SiO}_{2}$-Rice, b Aerosil $200^{\circledR}$ and clear solution: c Aerosil $200^{\circledR,}$ d LUDOX AS40 ${ }^{\circledR}$

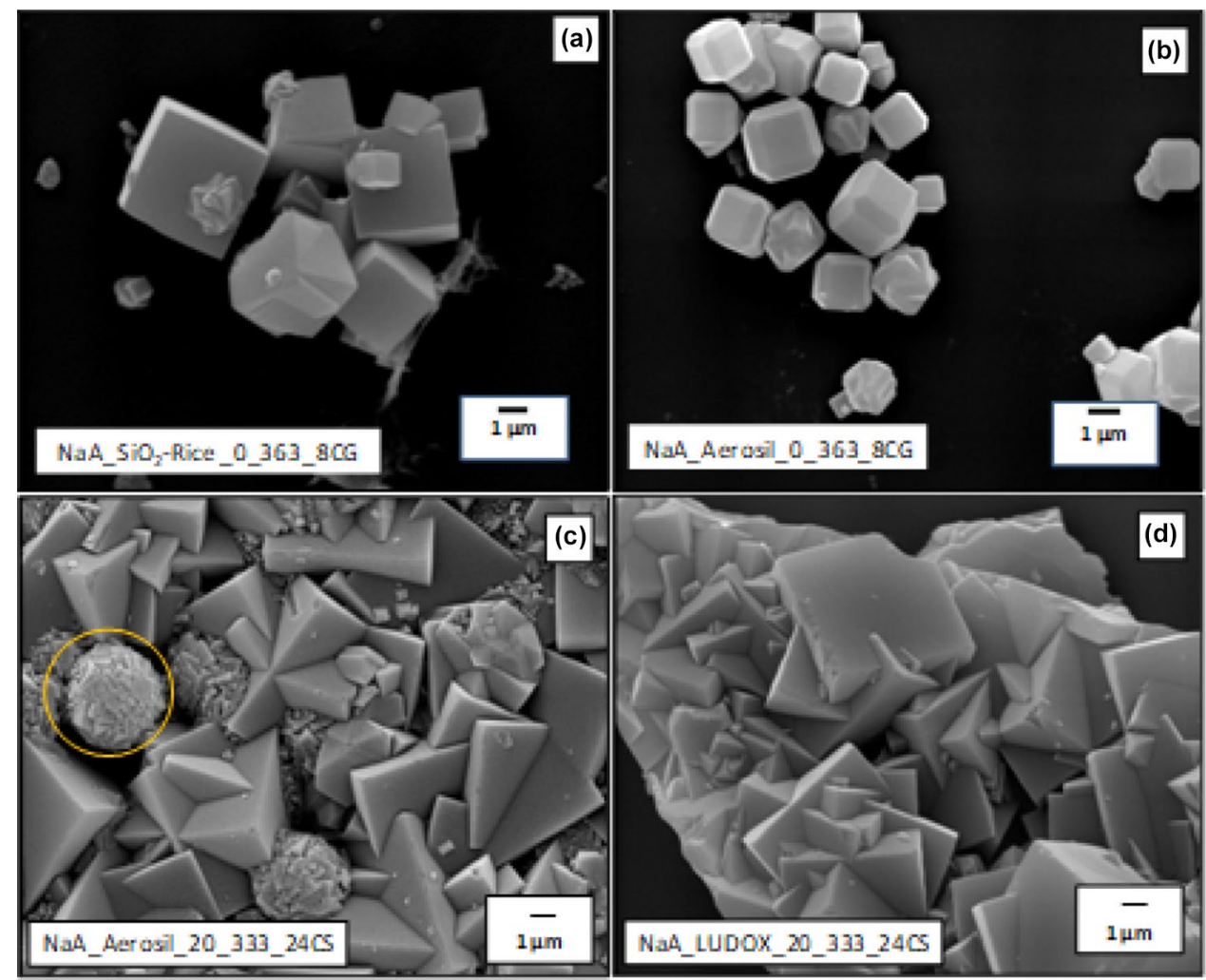

above, the $\mathrm{SiO}_{2}$-rice used in this work had about $3 \%$ of aluminum, which could also modify the nucleation kinetics of the zeolite, impacting on the morphology of the crystals. Basaldella et al. (1997) reported that, by changing the initial $\mathrm{SiO}_{2} / \mathrm{Al}_{2} \mathrm{O}_{3}$ ratio, it is possible to modify the size and morphology of the NaA zeolite crystals; they found that, by increasing the $\mathrm{SiO}_{2} / \mathrm{Al}_{2} \mathrm{O}_{3}$ ratio, the crystals became larger. The impurities in the silica source can also influence the morphology and properties of the synthesized zeolite. It has been suggested that the presence of aluminum ions in the silica source could produce hydroxylated anions such as $\left[\mathrm{HO}-\left(\mathrm{SiO}_{3}\right)^{\mathrm{m}-} \mathrm{AlO}_{2}-\left(\mathrm{SiO}_{3}\right)_{\mathrm{n}-} \mathrm{OH}^{(2 \mathrm{~m}+2 \mathrm{n}+1)-}\right]$, which behave like nuclei for the zeolite development before mixing the silicate and aluminate solutions (Freund 1976).

With respect to the clear solution synthesis, when Aerosil $200^{\circledR}$ was used, in addition to the cubic NaA zeolite phase, crystals with a different morphology were observed (Fig. 2c, yellow marks). These data are in agreement with the XRD measurements in which $\mathrm{NaX}$ zeolite was detected besides the NaA phase. When LUDOX AS40 ${ }^{\circledR}$ was used as the silica source, a pure NaA zeolite was observed in the SEM images. Probably, the use of LUDOX AS40 ${ }^{\circledR}$ (particle size 20-24 nm) could provide a higher nucleation rate, promoting the NaA phase formation instead of the $\mathrm{NaX}$.

Table 2 summarizes the characteristics of the $\mathrm{NaA}$ crystals obtained from all the synthesis conditions studied (Table 1). The $\mathrm{Si} / \mathrm{Al}$ and $\mathrm{Na} / \mathrm{Al}$ atomic ratios were determined by XRF. Note that the $\mathrm{Si} / \mathrm{Al}$ atomic ratio ranged between 1.17 and 1.21 for all the samples, independently of the synthesis route or the silicon source, so the change in the morphology can be connected to the different properties of the silicon source. On the other hand, the $\mathrm{Na} / \mathrm{Al}$ ratio of the samples synthesized from a clear solution was slightly higher than the $\mathrm{Na} / \mathrm{Al}$ ratio obtained from a concentrated gel. This
Table 2 Particle size, morphology, $\mathrm{Si} / \mathrm{Al}$ and $\mathrm{Na} / \mathrm{Al}$ atomic ratio for the synthesized powders

\begin{tabular}{llllll}
\hline Sample & Si source & Morphology & $\begin{array}{l}\text { Crystal } \\
\operatorname{size}^{\mathrm{a}}(\mu \mathrm{m})\end{array}$ & Si/Al & Na/Al \\
\hline NaA_Aerosil_0_363_8CG & Aerosil 200 & Truncated edge & $\sim 1-3$ & 1.21 & 1.14 \\
NaA_SiO2-Rice_0_363_8CG & $\mathrm{SiO}_{2}$-Rice & Sharp edge & $\sim 1-4$ & 1.17 & 1.16 \\
NaA_Aerosil_20_333_24CS & Aerosil 200 & Sharp edge & $\sim 4-5$ & 1.21 & 1.54 \\
NaA_LUDOX_20_333_24CS & LUDOX AS40 & Sharp edge & $\sim 4-5$ & 1.17 & 1.65 \\
\hline
\end{tabular}

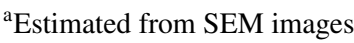


could be related to the excess of $\mathrm{NaOH}$ required to obtain a clear solution. For the NaA_LUDOX_20_333_24CS and NaA_Aerosil_20_333_24CS samples, EDS punctual analyses were also performed. The $\mathrm{Si} / \mathrm{Al}$ ratio of the cubic crystals was similar for the two samples $\sim 1.06$.

\section{Deposition of zeolite layers on porous stainless steel substrates}

\section{Effect of synthesis parameters on the growth of $\mathrm{NaA}$ zeolite on top of porous disks}

The optimization of zeolite deposition on stainless steel was performed on porous planar supports. As shown in our previous publication, the support geometry did not produce any effect on the structure and morphology of the NaA zeolite deposited (Martínez Galeano et al. 2016). Previous to the hydrothermal synthesis, the substrates were seeded with NaA nuclei and functionalized with APTES following the procedure reported in an earlier publication (Martínez Galeano et al. 2016) when a concentrated gel was used. The synthesis conditions of the studied membranes are summarized in Table 3. The NaA_Aerosil_D1 and NaA_SiO $2^{-}$ Rice_D2 samples shown in Table 3 were synthesized using a concentrated gel.

The surface morphology of the NaA_Aerosil_D1 and $\mathrm{NaA} \_\mathrm{SiO}_{2}$-Rice_D2 samples obtained from concentrated gel is shown in Fig. 3. Note that the sample prepared from $\mathrm{SiO}_{2}$-rice exhibits a high intergrowth of sharp edge crystals with higher homogeneity than the NaA_Aerosil_D1 sample, in agreement with the data obtained from the powders (Fig. 2).

The surface of the NaA_Aerosil_D1 sample shows regions with an irregular morphology; however, when pictures with a higher magnification were taken in these zones the presence of zeolite materials was observed (Fig. 3c).

From the XRD measurements, it was possible to confirm the formation of a pure NaA zeolite phase on top of the porous supports for both samples (Figure S1). In addition to the reflections assigned to the zeolite, a high intensity peak located at $43.3^{\circ}$ corresponding to the stainless steel support was observed (Figure S1).

The NaA_Aerosil_D3, NaA_LUDOX_D4, NaA LUDOX_D5, NaA_LUDOX_D6 and NaA_LUDOX_D7 membranes were obtained from a clear solution (Table 3). The number of depositions, APTES concentration and the hydrothermal synthesis pressure were varied to obtain a homogeneous zeolite layer from fumed-silica and colloidal silica. Figure 4 shows the membranes obtained from a clear solution. For the NaA_Aerosil_D3 sample, a continuous layer of highly intergrown crystals was formed on top of the support, showing a high particle size distribution (Fig. 4a). Note that an important amount of amorphous materials was present on the surface of the sample, which could be clearly observed in the magnified image (Fig. 4b). When LUDOX AS40 ${ }^{\circledR}$ was used instead of Aerosil $200^{\circledR}$ in the NaA_LUDOX_D4 sample, a poorly intergrown layer was deposited after the same number of hydrothermal cycles under the same conditions (Fig. 4c). The NaA_LUDOX_D4 sample did not develop a dense, compact layer on top of the support; non-amorphous materials and a higher crystal size homogeneity were observed compared with the NaA_Aerosil_D3. Taking into account that the surface functionalization with APTES improved the stability and adhesion of the zeolite layer to the support (Martínez Galeano et al. 2016), membrane NaA_LUDOX_D5 was synthesized. Note that after three hydrothermal depositions, a higher homogeneity

Table 3 Synthesis conditions of the membranes prepared by different synthesis routes

\begin{tabular}{|c|c|c|c|c|c|c|c|c|}
\hline Sample ${ }^{a}$ & Synthesis route & Si source & $\begin{array}{l}\text { Tem- } \\
\text { perature } \\
(\mathrm{K})\end{array}$ & Aged time (h) & Time (h) & Auto-clave & (APTES) $(\mathrm{mM})$ & Steps \\
\hline NaA_Aerosil_D1 & Concentrated gel & Aerosil $200^{\circledR}$ & 363 & 0 & 8 & No & 2.56 & 2 \\
\hline NaA_SiO 2 -Rice_D2 & Concentrated gel & $\mathrm{SiO}_{2}$-Rice & 363 & 0 & 8 & No & 2.56 & 2 \\
\hline NaA_Aerosil_20_333_24_D3 & Clear solution & Aerosil $200^{\circledR}$ & 333 & 20 & 24 & No & No & 3 \\
\hline NaA_LUDOX_20_333_24_D4 & Clear solution & LUDOX AS40 ${ }^{\circledR}$ & 333 & 20 & 24 & No & No & 3 \\
\hline NaA_LUDOX_20_333_24_D5 & Clear solution & LUDOX AS40 ${ }^{\circledR}$ & 333 & 20 & 24 & No & $2.56^{\mathrm{b}}$ & 3 \\
\hline NaA_LUDOX_20_333_24_D6 & Clear solution & LUDOX AS40 ${ }^{\circledR}$ & 333 & 20 & 24 & Yes & $2.56^{\mathrm{b}}$ & 3 \\
\hline NaA_LUDOX_20_333_24_D7 & Clear solution & LUDOX AS40 ${ }^{\circledR}$ & 333 & 20 & 24 & Yes & $5.12^{\mathrm{b}}$ & 2 \\
\hline NaA_Aerosil_T1 & Concentrated gel & Aerosil 200 ${ }^{\circledR}$ & 363 & 0 & 8 & No & 2.56 & 3 \\
\hline NaA_LUDOX_T2 & Clear solution & LUDOX AS40 $^{\circledR}$ & 333 & 20 & 24 & Yes & 5.12 & 2 \\
\hline NaA_SiO - -Rice_T3 & Concentrated gel & $\mathrm{SiO}_{2}$-Rice & 363 & 0 & 8 & No & 2.56 & 3 \\
\hline
\end{tabular}

${ }^{a}$ Nomenclature: NaA_X_Y where $\mathrm{X}$ refers to the Si source (Aerosil, $\mathrm{SiO}_{2}$-Rice and LUDOX), and Y to the membrane geometry (D for disks and $\mathrm{T}$ for tubes)

${ }^{\mathrm{b}}$ Samples modified with APTES in all the depositions 


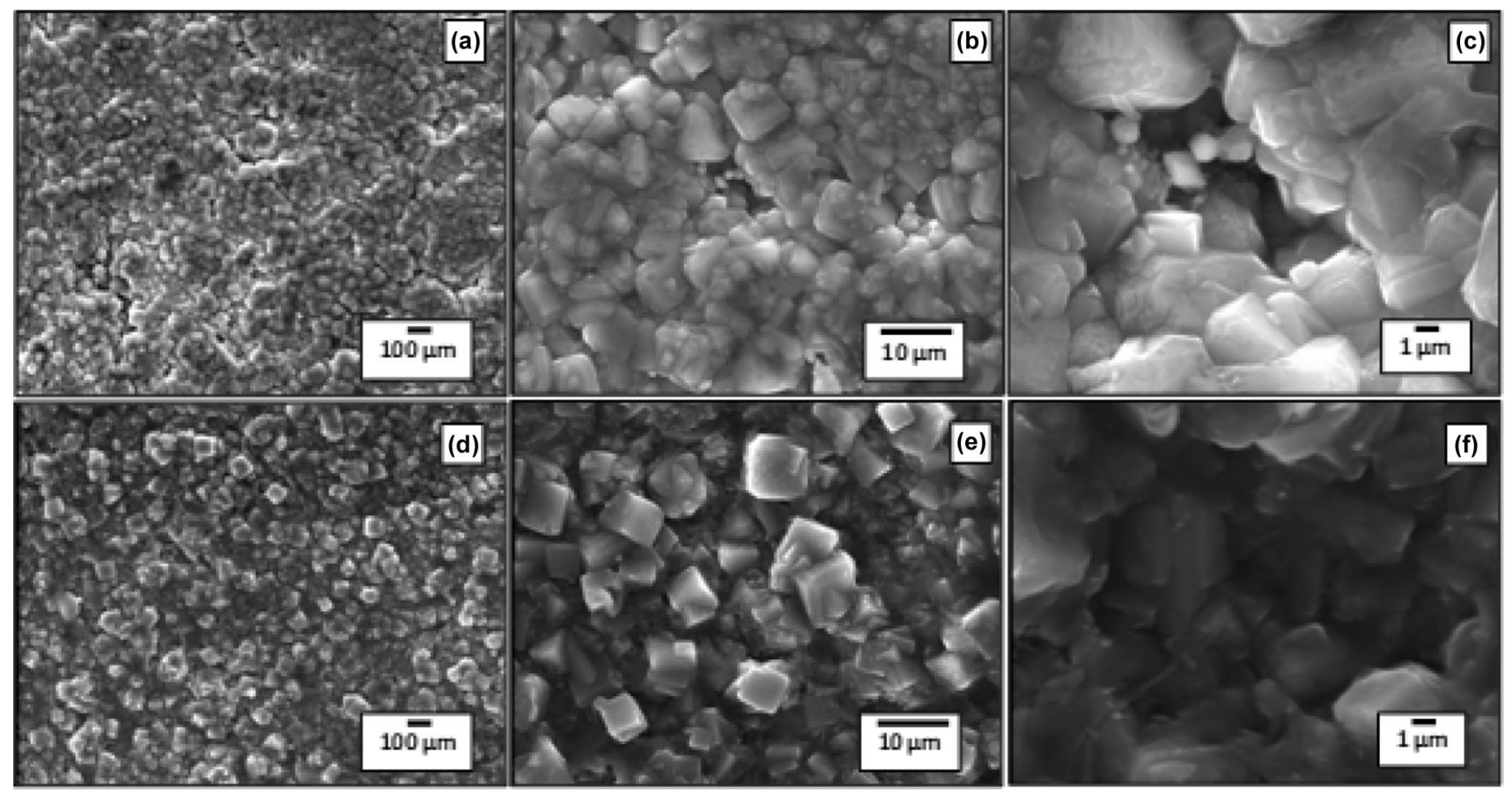

Fig. 3 Morphology of the membranes synthesized from a concentrated gel on top of porous stainless steel disks: effect of the $\mathrm{SiO}_{2}$ source. $\mathbf{a}, \mathbf{b}$, c NaA_Aerosil_D1, d, e, f NaA_SiO ${ }_{2}$-Rice_D2

was observed on the zeolite layer with cubic crystals and a small amount of amorphous materials around them (Fig. 4e).

The NaA_LUDOX_D6 membrane was synthesized in a Teflon autoclave vessel to obtain a more homogeneous membrane considering the effect of the self-generated pressure. It has been reported that the crystal growth using an autoclave depends on both the raw materials and their solubility and the equilibrium inside the vessel during the synthesis.

Using an autoclave, a higher pressure during the synthesis leads to a higher solubility and could improve homogeneity of the layer deposition on top of the support. Note that compared with sample NaA_LUDOX_D5, the use of an autoclave allows improving crystal density and intergrowth. However, the detachment of the zeolite layer from the stainless steel support was observed in some areas (Fig. 4g, inside), probably due to a low adhesion of the zeolite layer to the porous stainless steel. When the APTES concentration was twice that used for membrane NaA_LUDOX_D7, a significant improvement in the zeolite layer homogeneity was observed, without detachment from the support and higher intergrowth of the zeolite crystals (Fig. 4i, j, NaA_LUDOX_ D7 sample).

The effect of the Si source on the zeolite membrane morphology has not been widely addressed in the literature. Masuda et al. (1994) studied the effect of the Si source on the morphology of ZSM-5 layers. A uniform, well-intergrown layer was obtained using sodium silicate (Masuda et al. 1994). In addition, a previous work reported the synthesis of NaA zeolite membranes using the silica extracted from rice husk ash, where the zeolite was deposited by direct synthesis on $\mathrm{Al}_{2} \mathrm{O}_{3}$ disks as substrates. The authors found that the membrane thickness depended directly on the synthesis time. However, they did not report permeation measurements (Bhavornthanayod and Rungrojchaipon 2009).

\section{NaA zeolite membranes on tubular supports: permeation properties}

The optimized synthesis conditions for disk substrates were applied for the tubular membranes and are summarized in Table 3. The permeation measurements were carried out with porous stainless steel tubular membranes because this geometry allows a facile sealing with the permeation module (Martínez Galeano et al. 2016).

Hydrogen, methane and carbon dioxide single gas permeation properties were evaluated as a function of temperature. The data corresponding to the NaA_LUDOX_T2 synthesized from a clear solution are presented in Fig. 5. The permeation flux of $\mathrm{H}_{2}, \mathrm{CH}_{4}$ and $\mathrm{CO}_{2}$ decreased with temperature (Fig. 5a), which could probably be due to a higher contribution of permeation through defects. The $\mathrm{H}_{2} / \mathrm{CH}_{4}$ ideal separation factor at $453 \mathrm{~K}$ was lower than the Knudsen coefficient, while the $\mathrm{H}_{2} / \mathrm{CO}_{2}$ selectivity was slightly higher at the same temperature. 
Fig. 4 Morphology of the membranes synthesized from a clear solution on top of porous stainless steel disks: effect of the synthesis parameters
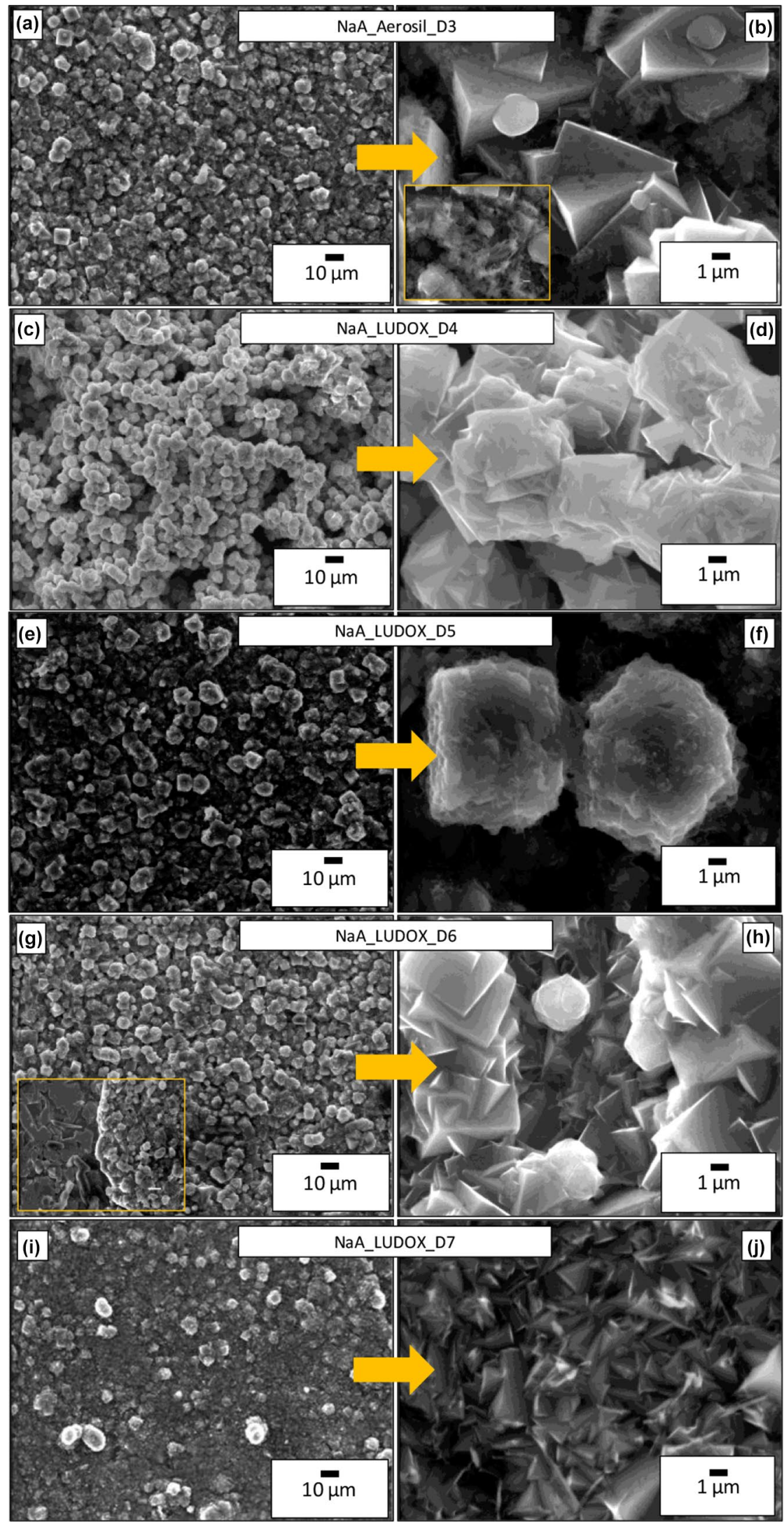

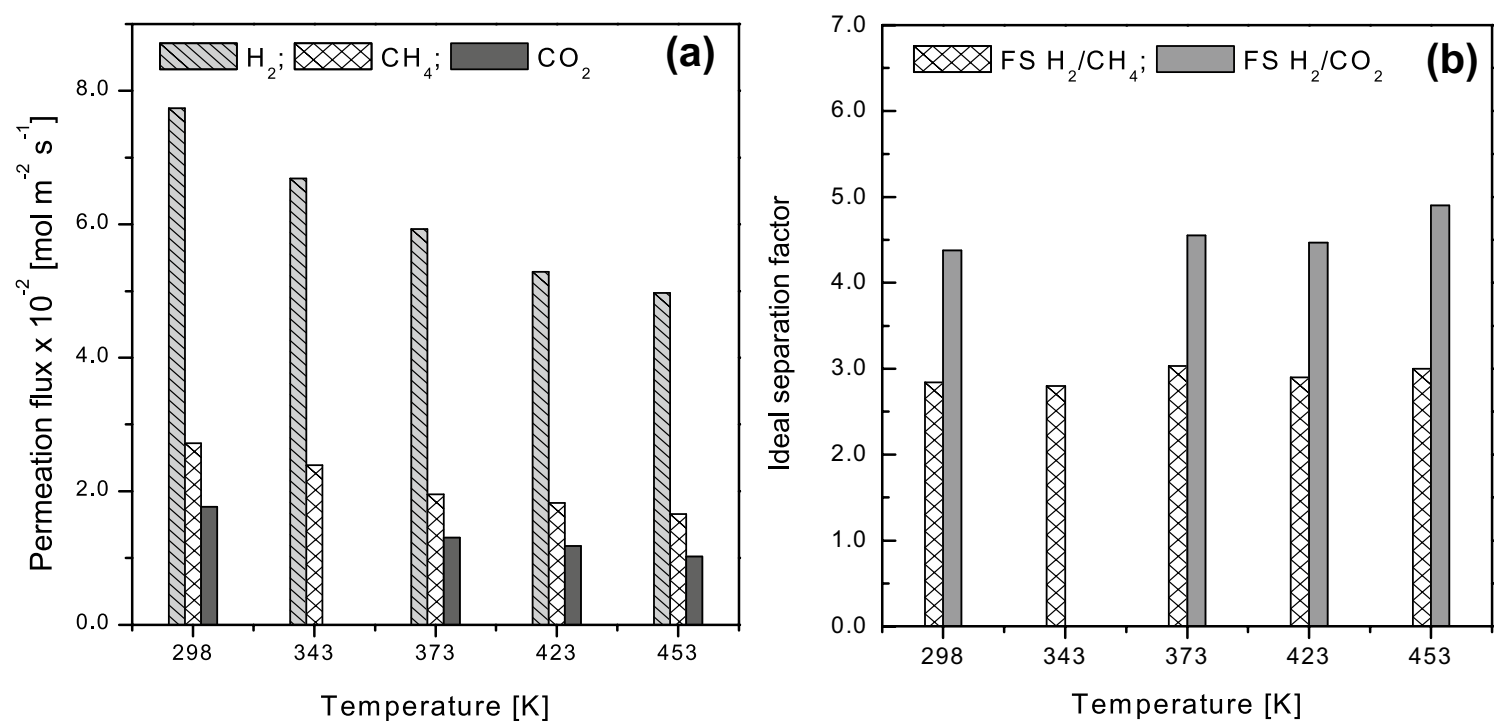

Fig. 5 Single gas permeation flux (a) and ideal separation factor (b) through the NaA_LUDOX_T2 membrane (clear solution)

The higher defect density in the membranes synthesized from a clear solution could be associated with the low adhesion of the film to the support related to the high $\mathrm{NaOH}$ content of the synthesis solution, even though a high concentration of APTES was employed to functionalize the support.

On the contrary, for the NaA_Aerosil_T1 and $\mathrm{NaA}_{-} \mathrm{SiO}_{2}-$ Rice_T3 membranes, the flux increased with temperature, which could be an indication of a higher zeolitic contribution to the overall flux (Fig. 6). A broader discussion about the zeolitic contribution is presented in the following section. Note that the membrane synthesized using rice husk ash as silica source showed the same behavior. The $\mathrm{H}_{2} / \mathrm{CO}_{2}$ ideal separation factor (5.4 and 5.7 for the NaA_Aerosil_T1 and NaA_SiO 2 -Rice_T3, respectively) was higher than that of $\mathrm{H}_{2} / \mathrm{CH}_{4}$ in the temperature range studied (Fig. 6c, d) and both were higher than the respective Knudsen coefficients $\left(\mathrm{H}_{2} / \mathrm{CO}_{2}=4.7\right.$ and $\left.\mathrm{H}_{2} / \mathrm{CH}_{4}=2.8\right)$. The best $\mathrm{H}_{2} / \mathrm{CO}_{2}$ ideal separation factors were reported by Huang et al. (2012) using a three-layered $\mathrm{NaA}$ zeolite membrane deposited on top of APTES-modified asymmetric $\mathrm{Al}_{2} \mathrm{O}_{3}$ disks. This membrane exhibited a hydrogen permeation flux of $1.6 \times 10^{-2}$ mol s${ }^{-1} \mathrm{~m}^{-2}$ at $373 \mathrm{~K}$ and $100 \mathrm{kPa}$, with a $\mathrm{H}_{2} / \mathrm{CO}_{2}$ ideal separation factor of 12 .

However, to this date there are no publications reporting $\mathrm{NaA}$ zeolite membranes supported on porous stainless steel tubes or symmetric ceramic substrates, showing ideal selectivity higher than the Knudsen coefficient. As shown in Fig. $6 \mathrm{~b}, \mathrm{~d}$, the membrane synthesized using rice husk ash as silica source and three hydrothermal syntheses $\left(\mathrm{NaA}_{-} \mathrm{SiO}_{2}-\right.$ Rice_T3) exhibited the same behavior with temperature as the NaA_Aerosil_T1 membrane. This membrane exhibited similar $\mathrm{H}_{2} / \mathrm{CO}_{2}$ and $\mathrm{H}_{2} / \mathrm{CH}_{4}$ ideal separation factors at the same temperature and $\Delta \mathrm{P}$ as the membrane synthesized using Aerosil $200^{\circledR}$. However, the anchoring and growth of $\mathrm{NaA}$ zeolite films on stainless steel substrates should still be improved to increase the selectivity of the composite membranes.

\section{Zeolitic and non-zeolitic contribution to the overall flux}

The selectivities so far reported for NaA zeolite membranes slightly exceed the Knudsen diffusion coefficients, indicating a predominance of this mechanism over the molecular sieve (Xu et al. 2018; Kondo et al. 1997; Aoki et al. 1998, 2000; Chen et al. 2005; Wei et al. 2017). In general, these low selectivities are attributed to the gas permeation through the non-zeolitic pores (intercrystalline defects in the zeolite film). The non-zeolitic pores could be formed by different causes: (1) the dehydration process of zeolite $\mathrm{NaA}$, which could cause cracking and/or contraction of the structure; (2) the non-homogeneous growth of zeolite films on macroporous substrates; (3) the expansion-contraction of the network in the presence of other gases (Chen et al. 2005; Sorenson et al. 2010, 2011). On the other hand, the factors that influence the formation of continuous and defect-free zeolite films have been analyzed in the literature. Zah et al. (2007) explained that there are thermodynamic constraints that restrict crystal intergrowth. Huang et al. (2012) reported that it is difficult to achieve a good intergrowth of $\mathrm{NaA}$ zeolite crystals due to the strong negative charge (zeta potential) of the crystal building units.

Considering what is explained above, the gas transport through a zeolite membrane could be described as a combination of two main contributions: (1) the gas passing through the zeolite pores, known as zeolitic or intracrystalline flux 


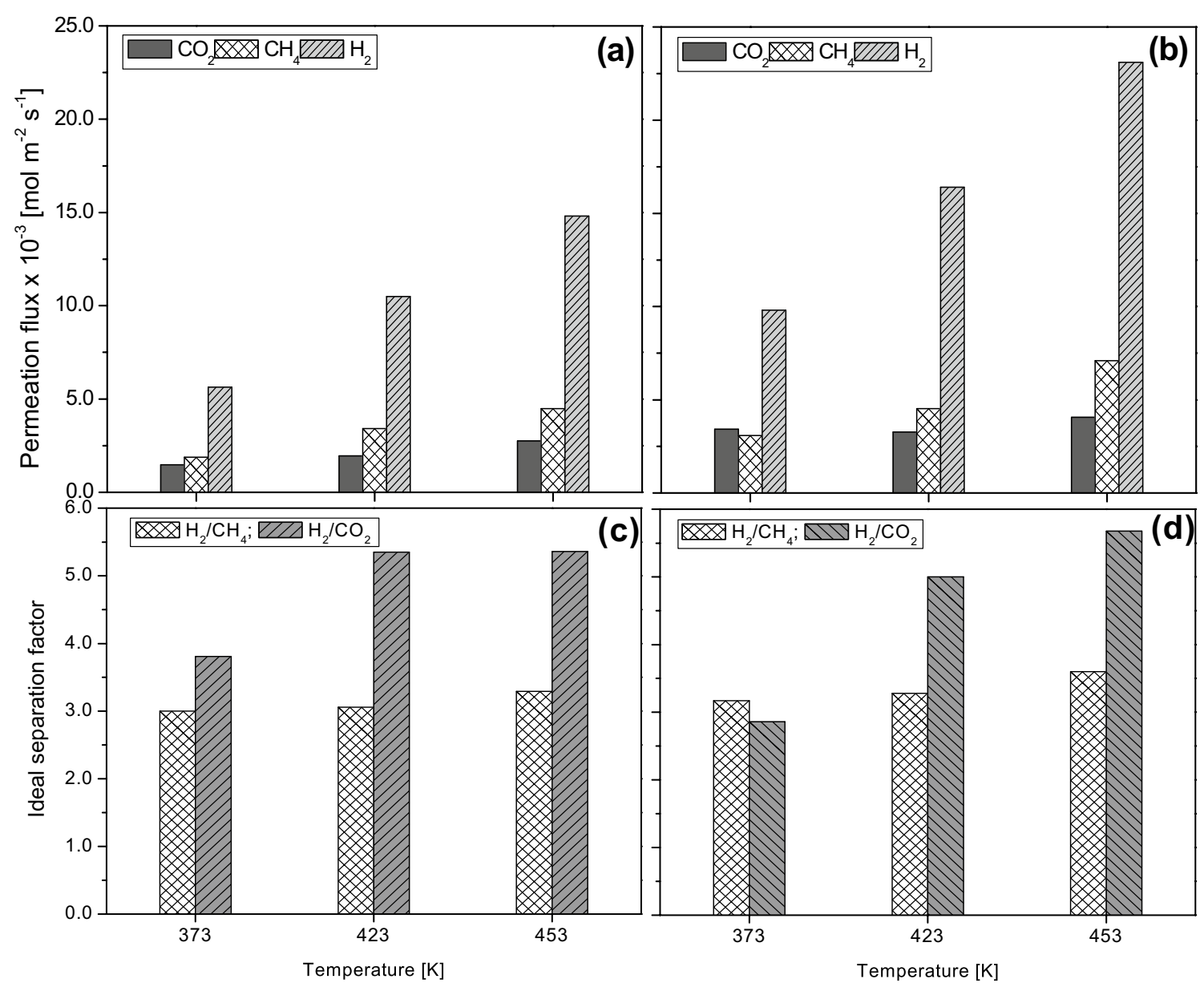

Fig. 6 Single gas permeation flux and ideal separation factor. a, $\mathbf{c}$ through the NaA_Aerosil_T1 membrane (concentrated gel), b, $\mathbf{d}$ through the NaA_SiO2-Rice_T3 membrane (concentrated gel)

and (2) the flux through the defect described as non-zeolitic or intercrystalline (Hosseinzadeh Hejazi et al. 2011). The permeation flux through zeolite membranes has been well described in the literature by the Maxwell-Stefan mechanism (Krishna and Baur 2003); Hosseinzadeh Hejazi et al. (2011) reported the fitting of the single gas permeation $\left(\mathrm{H}_{2} /\right.$ $\mathrm{CO}_{2}$ ) through natural zeolite membranes, where the zeolitic flux of a gas can be expressed by the following equation:

$N_{i, z}=\frac{-\rho q_{s} D_{i, 0}}{\Delta X} \exp \left[\left(\frac{E_{i}^{D}}{R}\right)\left(\frac{1}{T_{0}}-\frac{1}{T}\right)\right] \ln \left(\frac{1+b_{i} P_{\text {permeate }}}{1+b_{i} P_{\text {feed }}}\right)$

where $N_{i, z}$ is the molar flux of component i through zeolite pores $\left(\mathrm{mol} \mathrm{m}^{-2} \mathrm{~s}^{-1}\right), \rho$ the zeolite density $\left(\mathrm{kg} \mathrm{m}^{-3}\right), q_{s}$ the saturation adsorption capacity $\left(\mathrm{mol} \mathrm{kg}^{-1}\right), D_{i, 0}$ the diffusivity of component $\mathrm{i}$ at zero loading $\left(\mathrm{m}^{2} \mathrm{~s}^{-1}\right), \Delta X$ the thickness of the zeolite film (m), $E_{i}^{D}$ the activation energy of component i $\left(\mathrm{J} \mathrm{mol}^{-1}\right), R$ the ideal gas constant $\left(\mathrm{J} \mathrm{mol}^{-1} \mathrm{~K}^{-1}\right), T_{0}$ the reference temperature $(\mathrm{K}), T$ the temperature $(\mathrm{K}), b_{i}$ the
Langmuir adsorption constant of component $\mathrm{i}\left(\mathrm{Pa}^{-1}\right), b_{i, 0}$ the Langmuir adsorption constant of component $\mathrm{i}$ at the reference temperature $\left(\mathrm{Pa}^{-1}\right)$.

The dependence of $b i$ with temperature is given by Eq. 3:

$b_{i}=b_{i, 0} \exp \left[\left(\frac{\Delta H_{i}}{R}\right)\left(\frac{1}{T_{0}}-\frac{1}{T}\right)\right]$

where $\Delta H_{i}$ is the enthalpy of adsorption of component $\mathrm{i}$ $\left(\mathrm{J} \mathrm{mol}{ }^{-1}\right)$.

On the other hand, the mass transport through the defects is governed by the Knudsen and viscous flux mechanisms. The Knudsen and viscous contributions over a porous media (considering unidirectional flux) can be expressed by Eqs. 4 and 5, respectively:

$N_{i, k}=\frac{1}{\tau} \frac{1}{\Delta X} 97 r_{i} \sqrt{\frac{T}{M}} \frac{\Delta P_{i}}{R T}$ 
$N_{i, v}=\frac{1}{\Delta X} \frac{r_{i}^{2} P_{m}}{8 v} \frac{\Delta P}{R T}$

where $N_{i, k}$ is the Knudsen flux ( $\mathrm{mol} \mathrm{m}^{-2} \mathrm{~s}^{-1}$ ), $N_{i, v}$ is the viscous flux ( $\mathrm{mol} \mathrm{m}^{-2} \mathrm{~s}^{-1}$ ), $\tau$ is the membrane tortuosity, $r_{i}$ is the defect size (m), $M$ is the molecular weight $\left(\mathrm{g} \mathrm{mol}^{-1}\right), P_{i}$ is the partial pressure of component $\mathrm{i}(\mathrm{Pa}), P_{m}$ is the mean pressure $(\mathrm{Pa}), v$ is the viscosity $(\mathrm{Pa} \mathrm{s}), P$ is the pressure $(\mathrm{Pa})$.

Total flux through the membrane is due to the sum of Eqs. 2, 4 and 5; the overall flux is described by:

$$
\begin{aligned}
N_{i, t}= & -\varepsilon \frac{\rho q_{s} D_{i, 0}}{\Delta X} \exp \left[\left(\frac{E_{i}^{D}}{R}\right)\left(\frac{1}{T_{0}}-\frac{1}{T}\right)\right] \ln \left(\frac{1+b_{i} P_{\text {permeado }}}{1+b_{i} P_{\text {alimentación }}}\right) \\
& +\frac{(1-\varepsilon)}{\tau} \frac{1}{\Delta X} \frac{2 r_{i}}{3} \sqrt{\frac{8000 R}{M T}} \frac{\Delta P_{i}}{R}+\frac{(1-\varepsilon)}{\tau} \frac{1}{\Delta X} \frac{r_{i}^{2}}{8 R} \frac{P_{m}}{v} \frac{\Delta P}{T}
\end{aligned}
$$

where $\varepsilon=\frac{A_{z}}{A_{t}}$ is the porosity of the membrane, $A_{z}$ : zeolite open pore area $\left(\mathrm{m}^{2}\right)$ and $A_{t}$ : total area of the membrane $\left(\mathrm{m}^{2}\right)$.

Due to the complexity of experimentally obtaining or estimating the values of parameters $\varepsilon, \tau \mathrm{y} r_{i}$ as well as the membrane thickness $\Delta \mathrm{X}$, we defined three parameters (A, B and $C$ ) in which these variables are included. Figure 7 shows the cross-section of the tubular NaA_Aerosil_T1 membrane. The NaA zeolite penetrates in the pore structure of the stainless steel substrate by approximately $40 \mu \mathrm{m}$, depending on the surface morphology. Note that the EDS analysis showed the presence of $\mathrm{Si}$ and $\mathrm{Al}$ with an atomic ratio close to 1 . In addition, a poorly defined zeolite layer on top of the substrate surface can be observed.

Parameters A, B and C are defined by Eqs. 7-9:

$$
A=\varepsilon \frac{\rho q_{s} D_{i, 0}}{\Delta X} \ln \left(\frac{1+b_{i} P_{\text {permeado }}}{1+b_{i} P_{\text {alimentación }}}\right)
$$

$B=\frac{(1-\varepsilon)}{\tau} \frac{1}{\Delta X} \frac{2 r_{i}}{3} \sqrt{\frac{8000}{\pi R}}$

$$
C=\frac{(1-\varepsilon)}{\tau} \frac{1}{\Delta X} \frac{r_{i}^{2}}{8 R}
$$

As can be observed from Eq. $3, b_{i}$ depends on temperature. However, the variation of the term $\ln \left(\frac{1+b_{i} P_{\text {permeado }}}{1+b_{i} P_{\text {alimentacion }}}\right)$ with temperature is negligible since the product $b_{i} * P \gg 1$ in the pressure range studied. These data were estimated from $\mathrm{CO}_{2}$ adsorption isotherms taken at different temperatures using the Langmuir model. The data are summarized in Table 4.

The final expression to the treatment of the data is:

$$
N_{i, t}=-A \exp \left[\left(\frac{E_{i}^{D}}{R}\right)\left(\frac{1}{T_{0}}-\frac{1}{T}\right)\right]+B \sqrt{\frac{1}{M T}} \Delta P_{i}+C \frac{P_{m}}{v} \frac{\Delta P}{T} .
$$
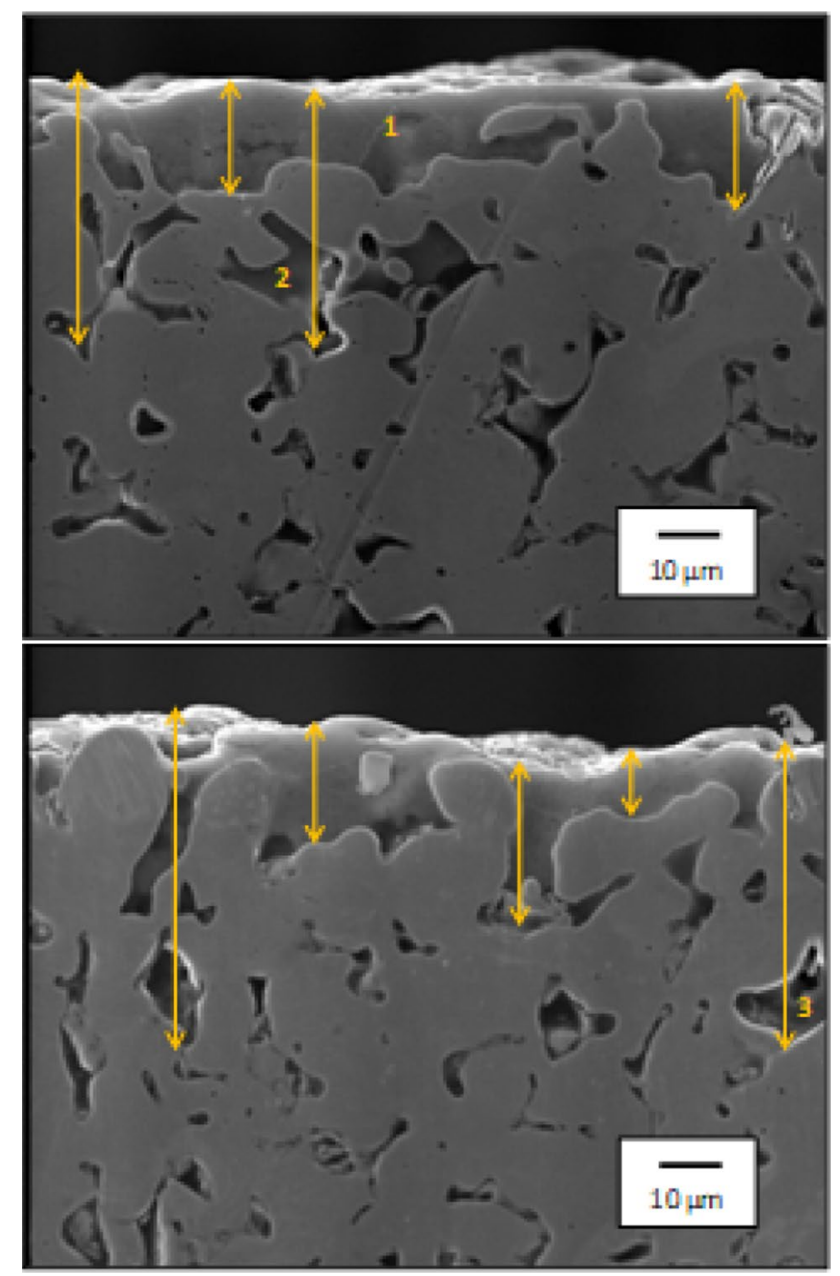

Fig. 7 Cross-section SEM images of the NaA_Aerosil_T1 membrane in different regions. The numbers correspond to the EDS analysis of $\mathrm{Si} / \mathrm{Al}$ ratio, 1, 2, 3

The contribution of each mechanism to the overall flux was estimated only for membranes prepared using concentrated gel, taking into account that they exhibited ideal selectivities higher than the Knudsen coefficients.

The analysis of the permeance data as a function of the pressure difference across the membrane suggests that, for the membrane synthesized from a concentrated gel, the contribution of the viscous flux was negligible (Figure S2). In agreement with what is said above, the flux through these membranes were fitted considering the zeolitic and Knudsen contributions.

The experimental data were fitted using MATLAB software, through the curve fitting tool, introducing Eq. 10; the iteration algorithm was the Trust Region. As an adjustment of a good fit, the condition of the Knudsen separation factor $\left(K_{\mathrm{H}_{2} / \mathrm{CO}_{2}}=4.7\right)$ must be satisfied and, as a statistical measure of the validity of the data fit, the $\mathrm{R}^{2}$ determination coefficient was taken into account. 
Table 4 Value of $b_{i}$ at different temperatures

\begin{tabular}{lll}
\hline Temperature $(\mathrm{K})$ & $b_{i}\left(\mathrm{~Pa}^{-1}\right)$ & $\ln \left(\frac{1+b_{i} P_{\text {permate }}}{1+b_{i} P_{\text {feed }}}\right)$ \\
\hline 373 & & -0.687 \\
423 & $4.18 \times 10^{-3}$ & -0.686 \\
453 & $3.19 \times 10^{-3}$ & -0.686 \\
\hline
\end{tabular}

$b_{i, 0[298 \mathrm{~K}]}=7.44 \times 10^{-3} \Delta H_{\mathrm{CO}_{2}}=-7.04 \mathrm{~kJ} \mathrm{~mol}^{-1} P_{\text {permeate }}=101.3 \mathrm{kPa} P_{\text {feed }}=201.3 \mathrm{kPa}$

The activation energy used for $\mathrm{CO}_{2}\left(E_{\mathrm{CO}_{2}}^{\mathrm{D}}\right)$ was $30 \mathrm{~kJ} \mathrm{~mol}^{-1}$, as reported by Ma and Mancel (1972). These authors calculated the activation energy from chromatographic techniques using the equation developed by Van Deemter, Zuiderweg, and Klinkenberg and several studies reported the same value (Ruthven 2012; Kanezashi and Lin
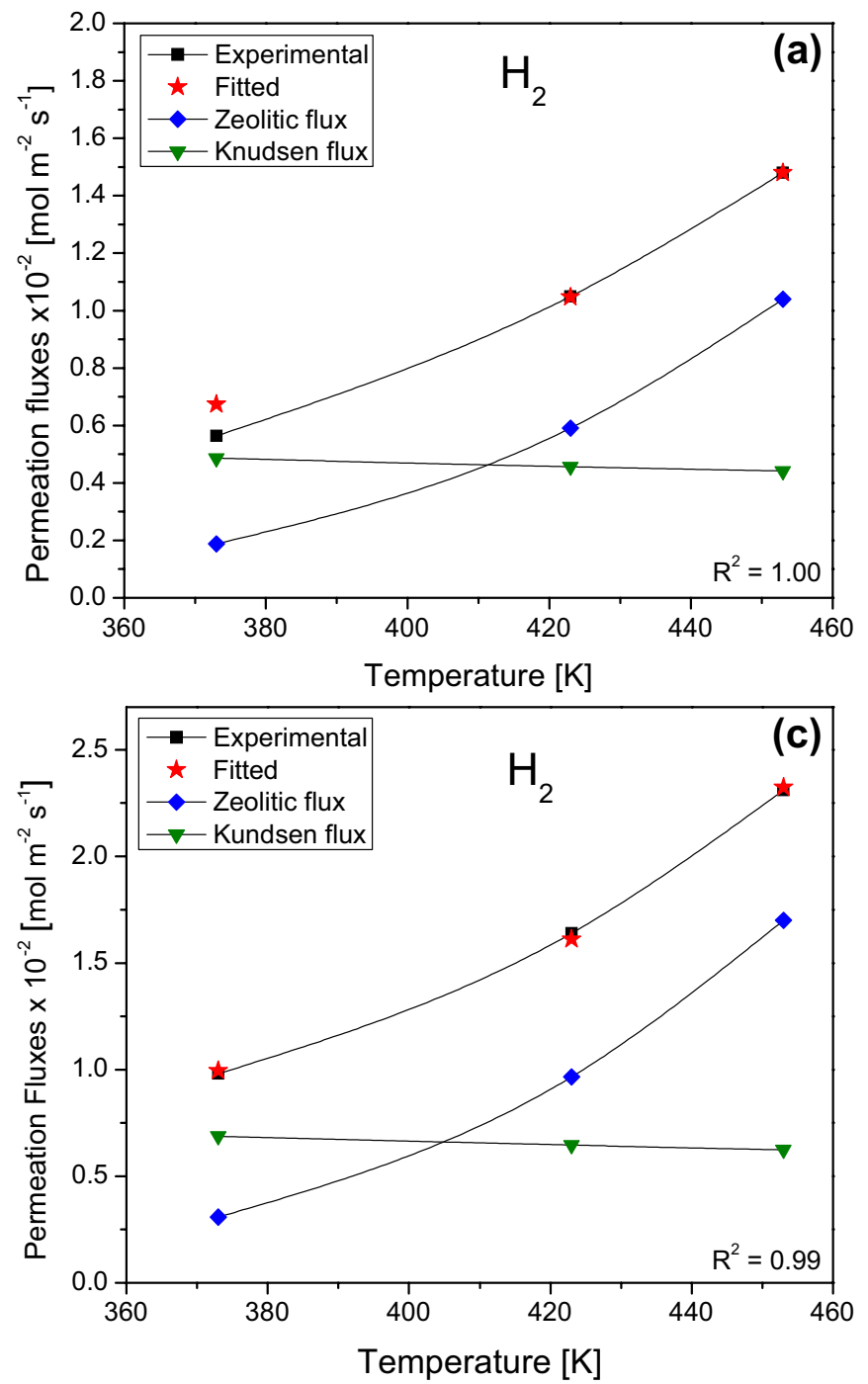

2009). For the experimental permeation data of $\mathrm{CO}_{2}$, the best fit was achieved employing this energy value (Fig. 8b, d). In the case of the activation energy of hydrogen on zeolite $\mathrm{NaA}$, the data available in the literature cover a wide range between 2 and $119 \mathrm{~kJ} \mathrm{~mol}^{-1}$ (Hosseinzadeh Hejazi et al. 2011; Sorenson et al. 2011; Ruthven 2012; Kanezashi and Lin 2009; Kahn et al. 1989; Fraenkel 1981). Several
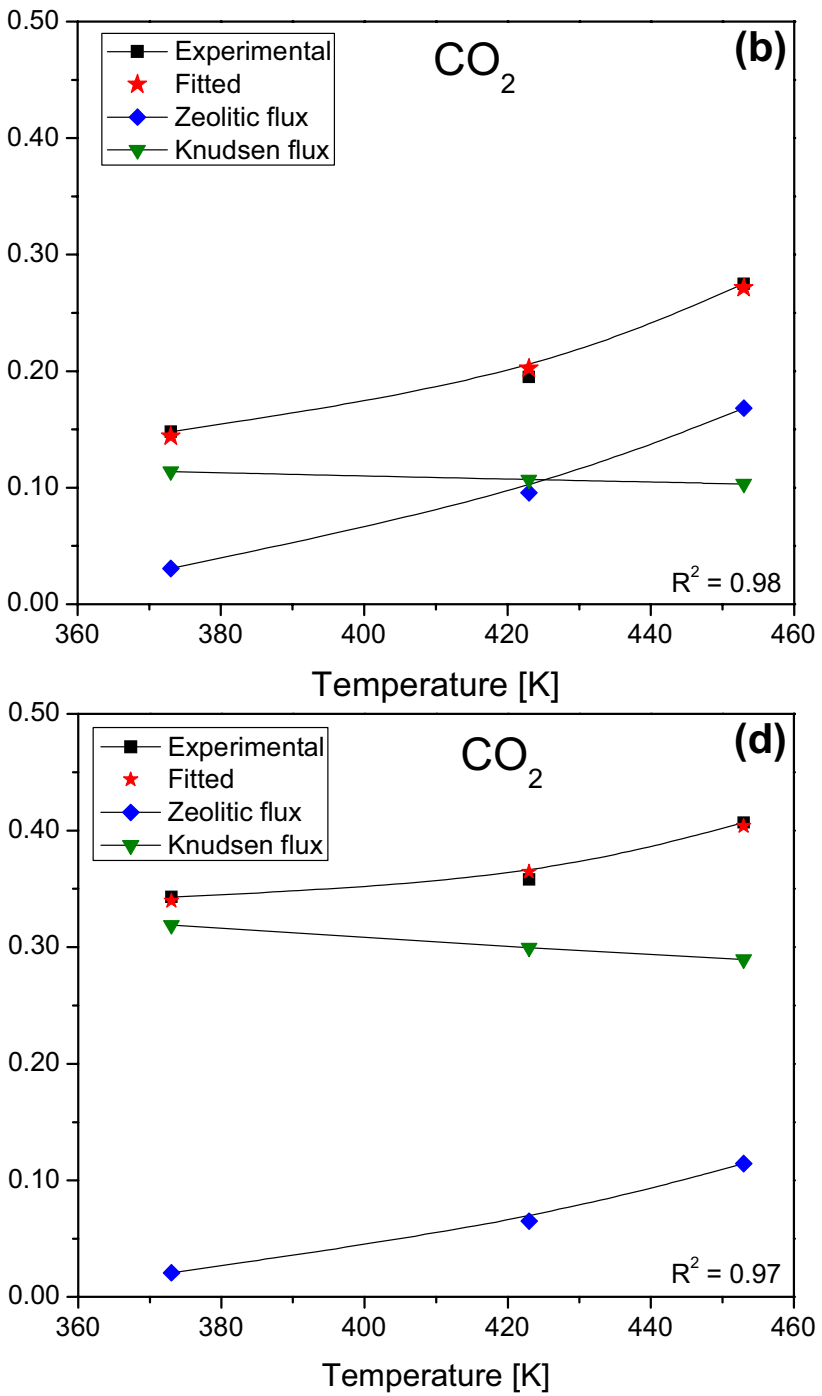

Fig. 8 Experimental and fitted permeation fluxes of $\mathrm{H}_{2}$ and $\mathrm{CO}_{2}$. a, b NaA_Aerosil_T1; $\mathbf{c}, \mathbf{d}$ NaA_SiO 2 -Rice_T3 membranes at $\Delta \mathrm{P}=100 \mathrm{kPa}$ 
Table 5 Constants A, B and C for NaA_Aerosil_T1 and NaA_SiO ${ }_{2}$ Rice_T3 membranes

\begin{tabular}{llllll}
\hline Membrane & $\mathrm{A}\left(\mathrm{mol} \mathrm{m}{ }^{-2} \mathrm{~s}\right)$ & & \multicolumn{3}{c}{$\mathrm{B}\left[\left(\mathrm{mol} \mathrm{K} \mathrm{J}^{-1}\right)^{0.5}\right]$} \\
\cline { 2 - 3 } \cline { 5 - 6 } & $\mathrm{H}_{2}$ & $\mathrm{CO}_{2}$ & & $\mathrm{H}_{2}$ & $\mathrm{CO}_{2}$ \\
\hline NaA_Asil_T1 & $1.65 \times 10^{-4}$ & $2.67 \times 10^{-5}$ & & $1.31 \times 10^{-6}$ & $1.44 \times 10^{-6}$ \\
NaA_SiO $2^{-}$ & $2.69 \times 10^{-4}$ & $1.82 \times 10^{-5}$ & $1.85 \times 10^{-6}$ & $4.03 \times 10^{-6}$ \\
Rice_T3 & & & & \\
\hline
\end{tabular}

values of activation energy were analyzed and it was found that the best fit was obtained using an $E_{\mathrm{H}_{2}}^{D}$ equal to $30 \mathrm{~kJ} \mathrm{~mol}^{-1}$. For both gases, a good adjustment was obtained with the same activation energy. Ruthven (2012) reported an analysis of the variation of the activation energy with the molecular diameter, finding that for small molecules $\mathrm{N}_{2}$, $\mathrm{CO}_{2}, \mathrm{H}_{2}, \mathrm{CH}_{4}$, the $E_{\mathrm{i}}^{D}$ are very similar $\left(\sim 25 \mathrm{~kJ} \mathrm{~mol}^{-1}\right)$ despite the variation in the molecular diameter. This analysis is in agreement with our results.

Table 5 shows the values of parameters $\mathrm{A}$ and $\mathrm{B}$ obtained for the NaA_Aerosil_T1 and NaA_SiO 2 -Rice_T3 membranes. Comparing the values obtained for $\mathrm{H}_{2}$ and $\mathrm{CO}_{2}$, it can be seen that parameter $\mathrm{A}$ for $\mathrm{H}_{2}$ is higher, which could be associated with the greater diffusivity $\left(D_{i, 0}\right)$ of $\mathrm{H}_{2}$ compared to $\mathrm{CO}_{2}$. The value of parameter $\mathrm{B}$ was similar for both gases, which may be due to the fact that the molecules permeate through intercrystalline membrane defects (nonzeolitic pores), independently of the molecular size, which is in agreement with Eq. 8. Parameter B, depends mainly on the morphological properties of the membrane.

Figure 8 shows the adjustment results for NaA_Aerosil_T1, and NaA_SiO 2 -Rice_T3 membranes. As can be observed, the fitting is in good agreement with the experimental data independently of the sources of silicon employed. In the case of $\mathrm{H}_{2}$, the total permeance increased with temperature due to the effect of temperature on the zeolitic flux (Eq. 1) according to the Maxwell-Stephan theory. The permeation flux of $\mathrm{CO}_{2}$ also presented an increase with temperature; however it was lower than the $\mathrm{H}_{2}$ increase. This can be due to the lower diffusivity of $\mathrm{CO}_{2}$ compared with $\mathrm{H}_{2}$. As a consequence, the $\mathrm{H}_{2} / \mathrm{CO}_{2}$ separation factors were higher than the Knudsen factor achieved at $453 \mathrm{~K}$. The parity plot presented in Fig. 9 shows that a good agreement was obtained between the experimental $\mathrm{H}_{2}$ flux and those obtained from the fitting.

\section{Conclusions}

Pure phase $\mathrm{NaA}$ zeolite powders were synthesized from a concentrated gel using both $\mathrm{SiO}_{2}$ extracted from rice husk ash and Aerosil $200^{\circledR}$. The silica source had a significant

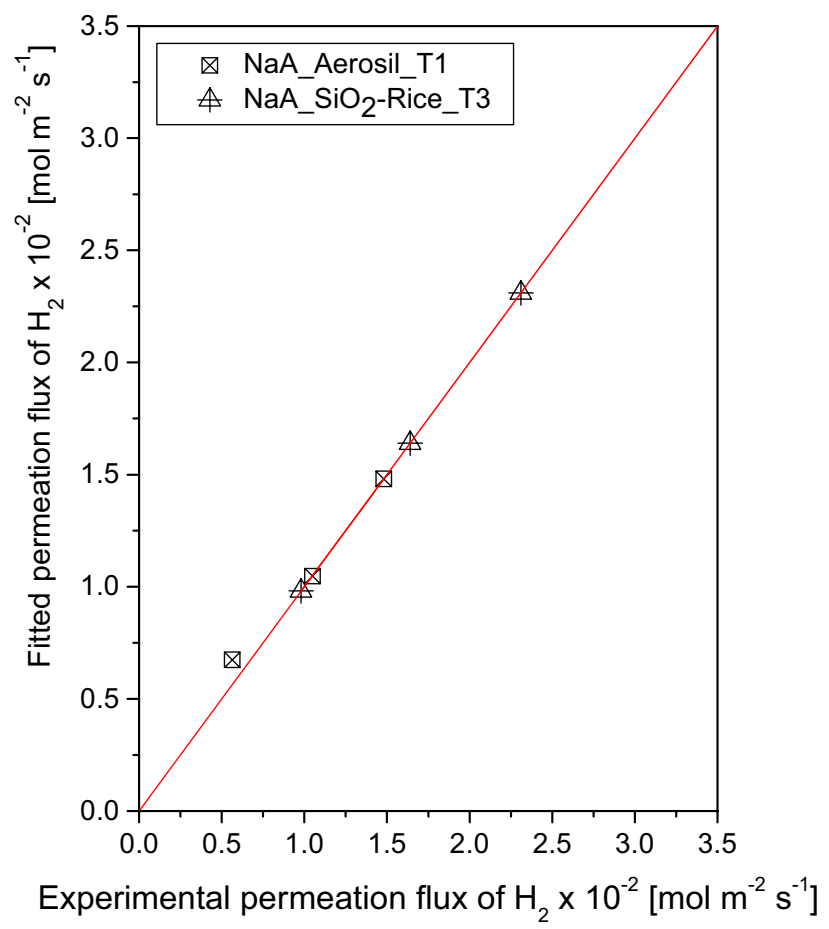

Fig. 9 Parity plot of measured versus fitted permeation flux of $\mathrm{H}_{2}$ in tubular membranes at $453 \mathrm{~K}$ and $\Delta \mathrm{P}=100 \mathrm{kPa}$

effect on the morphology and size of the crystals. A sharp edge cubic morphology was obtained using the $\mathrm{SiO}_{2}$-rice while edge-truncated crystals developed using Aerosil $200^{\circledR}$. Using $\mathrm{SiO}_{2}$ extracted from the rich husk ash, it was possible to obtain pure phase NaA zeolite in powders. This is an important issue considering the use of agro-industrial wastes to obtain products with higher added value.

$\mathrm{NaA}$ and $\mathrm{NaX}$ mixture phases were obtained from a clear solution using Aerosil $200^{\circledR}$, while a pure NaA phase was successively achieved with a colloidal suspension of silica after $20 \mathrm{~h}$ of aging at room temperature followed by hydrothermal synthesis at $333 \mathrm{~K}$ during $24 \mathrm{~h}$. The optimized synthesis conditions were applied for the synthesis of $\mathrm{NaA}$ zeolite layers on top of porous stainless steel disks or on the outer surface of tubular supports. Films with a high homogeneity and defect free were obtained for all silicon sources employed. The modification with APTES enhanced the adhesion of the zeolitic film to the metallic support. In the case of the clear solution synthesis, it was necessary to double the concentration of APTES in order to avoid the detachment of the film.

Despite the silica source used, the $\mathrm{H}_{2}, \mathrm{CH}_{4}$ and $\mathrm{CO}_{2}$ permeation fluxes increased with temperature for the membranes synthesized using a concentrated gel as a reactant mixture. Selectivity values similar to those published for 
$\mathrm{NaA}$ zeolite membranes based on ceramic substrates were obtained using zeolite layers deposited on porous stainless steel tubes. In addition, the membranes were stable for at least 15 days on stream, even after being exposed to heating and cooling cycles. From the curve fitting of the experimental data, the contribution of zeolitic and non-zeolitic flux was estimated. For the membranes synthesized from a concentrated gel, $\mathrm{CO}_{2}$ showed a higher contribution of the Knudsen mechanism to the overall flux. However, a greater contribution of the zeolitic flux was observed in the case of $\mathrm{H}_{2}$.

Acknowledgements The authors wish to acknowledge the financial support received from Universidad Nacional del Litoral, CONICET and ANPCyT. Thanks are also given to Betina Faroldi and Luis Salazar Hoyos for providing the silica obtained from rice husk.

\section{References}

Aoki K, Kusakabe K, Morooka S (1998) Gas permeation properties of A-type zeolite membrane formed on porous substrate by hydrothermal synthesis. J Membr Sci 141:197-205

Aoki K, Kusakabe K, Morooka S (2000) Separation of gases with an A-type zeolite membrane. Ind Eng Chem Res 39:2245-2251

Ayele L, Pérez-Pariente J, Chebude Y, Diaz I (2016) Synthesis of zeolite A using kaolin from Ethiopia and its application in detergents. New J Chem 40:3440-3446

Basaldella EI, Kikot A, Tara JC (1997) Effect of aluminum concentration on crystal size and morphology in the synthesis of a $\mathrm{NaAl}$ zeolite. Mater Lett 31:83-86

Berenguer-Murcia A, Morallón E, Cazorla-Amorós D, Linares-Solano A (2005) Preparation of silicalite-1 layers on Pt-coated carbon materials: a possible electrochemical approach towards membrane reactors. Microporous Mesoporous Mater 78:159-167

Bhavornthanayod C, Rungrojchaipon P (2009) Synthesis of zeolite A membrane from rice husk ash. J Met Mater Miner 19:79-83

Chen X, Yang W, Liu J, Lin L (2005) Synthesis of zeolite NaA membranes with high permeance under microwave radiation on mesoporous-layer-modified macroporous substrates for gas separation. J Membr Sci 255:201-211

Database of Zeolite Structures: https://america.iza-structure.org/IZASC/framework.php?STC=FAU. Accessed 29 May 2020

Feng C, Khulbe KC, Matsuura T, Farnood R, Ismail AF (2015) Progress in zeolite/zeotype membranes. J Membr Sci Res 1:49-72

Fraenkel D (1981) Zeolitic encapsulation. Part 1-hydrogen diffusion in A-type zeolite encapsulates. J Chem Soc Faraday Trans 77:2029-2039

Freund EF (1976) Mechanism of the crystallization of zeolite X. J Cryst Growth 34:11-23

Gui T, Zhang F, Li Y, Xue Cui, Wu X, Zhu M, Hu N, Chen X, Kita H, Kondo M (2019) Scale-up of NaA zeolite membranes using reusable stainless steel tubes for dehydration in an industrial plant. J Membr Sci 583:180-189

Hosseinzadeh Hejazi SA, Avila AM, Kuznicki TM, Weizhu A, Kuznicki SM (2011) Characterization of natural zeolite membranes for $\mathrm{H}_{2} / \mathrm{CO}_{2}$ separations by single gas permeation. Ind Eng Chem Res 50:12717-12726

Hu N, Li Y, Zhong S, Wang B, Chen X (2016) Fluoride-mediated synthesis of high-flux chabazite membranes for pervaporation of ethanol using reusable macroporous stainless steel tubes. J Membr Sci 510:91-100
Huang A, Liang F, Steinbach F, Caro J (2010) Preparation and separation properties of LTA membranes by using 3-aminopropyltriethoxysilane as covalent linker. J Membr Sci 350:5-9

Huang A, Wang N, Caro J (2012) Synthesis of multi-layer zeolite LTA membranes with enhanced gas separation performance by using 3-aminopropyltriethoxysilane as interlayer. Microporous Mesoporous Mater 164:294-301

Kahn R, Cohen de Lara E, Viennet E (1989) Diffusivity of the hydrogen molecule sorbed in NaA zeolite by a neutron scattering experiment. J Chem Phys 91:5097-5107

Kanezashi M, Lin YS (2009) Gas permeation and diffusion characteristics of MFI-type zeolite membranes at high temperatures. J Phys Chem C 113:3767-3774

Katsuki H, Komarneni S (2009) Synthesis of Na-A and/or Na-X zeolite/porous carbon composites from carbonized rice husk. J Solid State Chem 182:1749-1975

Kondo M, Komori M, Kita H, Okamoto KI (1997) Tubular-type pervaporation module with zeolite NaA membrane. J Membr Sci 133:133-141

Krishna R, Baur R (2003) Modelling issues in zeolite based separation processes. Sep Purif Technol 33:213-254

Ma YH, Mancel C (1972) Diffusion studies of $\mathrm{CO}_{2}, \mathrm{NO}, \mathrm{NO}_{2}$, and $\mathrm{SO}_{2}$ on molecular sieve zeolites by gas chromatography. AIChE J 18:1148-1153

Martínez Galeano Y, Cornaglia L, Tarditi AM (2016) NaA zeolite membrane synthesized on top of APTES-modified porous stainless steel substrates. J Membr Sci 512:93-103

Masuda T, Sato A, Hara H, Kouno M, Hashimoto K (1994) Preparation of a dense ZSM-5 zeolite film on the outer surface of an alumina ceramic filter. Appl Catal A 111:143-150

Meise W, Schwochow FE (1973) Kinetic studies on the formation of zeolite A. In: Molecular sieves. Advances in Chemistry, vol 121, pp 169-178

Mohamed RM, Ismail AA, Kini G, Ibrahim IA, Koopman B (2009) Synthesis of highly ordered cubic zeolite A and its ion-exchange behavior. Colloids Surf A 348:87-92

Nair S, Tsapatsis M (2003) Synthesis and properties of zeolitic membranes. In: Handbook of zeolite science and technology, Marcel Dekker Inc, New York

Ng E-P, Lim GK, Khoo G-L, Tan K-H, Ooi BS, Adam F, Ling TC, Wong K-L (2015) Synthesis of colloidal stable Linde Type J (LTJ) zeolite nanocrystals from rice husk silica and their catalytic performance in Knoevenagel reaction. Mater Chem Phys 155:30-35

Pina MP, Mallada R, Arruebo M, Urbiztondo M, Santamaria J (2011) Zeolite films and membranes. Emerging applications. Microporous Mesoporous Mater 144:19-27

Ruthven DM (2012) Diffusion in type A zeolites: new insights from old data. Microporous Mesoporous Mater 162:69-79

Sorenson SG, Payzant EA, Noble RD, Falconer JL (2010) Influence of crystal expansion/contraction on zeolite membrane permeation. J Membr Sci 357:98-104

Sorenson SG, Payzant EA, Gibbons WT, Soydas B, Kita H, Noble RD, Falconer JL (2011) Influence of zeolite crystal expansion/ contraction on NaA zeolite membrane separations. J Membr Sci 366:413-420

Wei X-L, Liang S, Xu Y-Y, Sun Y-L, An J-F, Chao Z-S (2017) Patching $\mathrm{NaA}$ zeolite membrane by adding methylcellulose into the synthesis gel. J Membr Sci 530:240-249

Xu Y, Wei X, Liang S, Sun Y, Chao Z (2018) Synthesis of a ZSM-5/ $\mathrm{NaA}$ hybrid zeolite membrane using kaolin as a modification layer. New J Chem 42:6664-6672

Zah J, Krieg HM, Breytenbach JC (2007) Single gas permeation through composiotanally different zeolite $\mathrm{NaA}$ membranes: observations on the intercrystalline porosity in an unconventional, semicrystalline layer. J Membr Sci 287:300-310 
Zhang X, Tang D, Jiang G (2013a) Synthesis of zeolite NaA at room temperature: the effect of synthesis parameters on crystal size and its size distribution. Adv Powder Technol 14:689-696

Zhang X, Tang D, Zhang M, Yang R (2013b) Synthesis of NaX zeolite: influence of crystallization time, temperature and batch molar ratio $\mathrm{SiO}_{2} / \mathrm{Al}_{2} \mathrm{O}_{3}$ on the particulate properties of zeolite crystals. Powder Technol 235:322-328

Zhang F, Zheng Y, Hu L, Hu N, Kita H (2014) Preparation of high-flux zeolite $\mathrm{T}$ membranes using reusable macroporous stainless steel supports in fluoride media. J Membr Sci 456:107-116
Publisher's Note Springer Nature remains neutral with regard to jurisdictional claims in published maps and institutional affiliations. 